\title{
Ectopic somatotroph adenomas
}

Farida Chentli, Dia-Eddine Boudiaf, Said Azzoug .

Department of Endocrinology and Metabolic diseases, Bab El Oued teaching Hospital, Algiers, Algeria.

Introduction: ectopic somatotroph adenomas are very rare. Their mechanism is still debated. Our aim was to report 2 cases: One was located in the sphenoid sinus and/or clivus, and the other one in the supra sella area.

Case 1: A 45 year-old woman, was diagnosed as acromegaly by the family doctor. Growth hormone $(\mathrm{GH})=$ $44 \mathrm{ng} / \mathrm{ml}$, IGF1 $=504 \mathrm{ng} / \mathrm{ml}(150-350)$. Prolactin $(\mathrm{PRL})=37 \mathrm{ng} / \mathrm{ml}$. The rest of pituitary function was normal. Cerebral MRI showed a tumor measuring $16 \times 14 \mathrm{~mm}$ located in the sphenoid sinus/ clivus with pituitary empty sella.

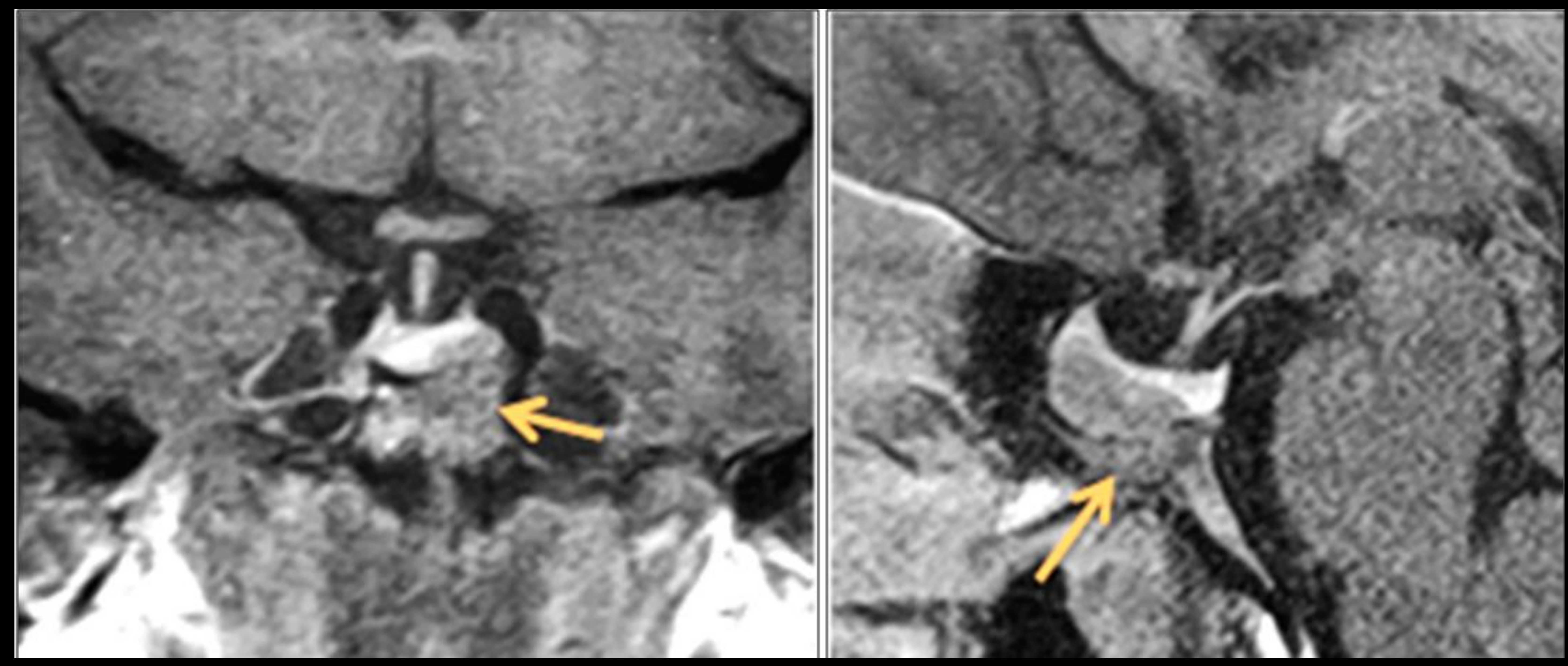

Case 2: A 24 year-old woman consulted for secondary amenorrhea. Clinical examination argued for acromegaly. Hormonal assessment confirmed the diagnosis as GH=76ng/ml, IGF1= 563ng/ml (105-217), PRL $=15 \mathrm{ng} / \mathrm{ml}$. The rest of pituitary function was normal. MRI showed an intra and supra sella tumor measuring $24 \times 19 \times 16 \mathrm{~mm}$ without cavernous system invasion or sella floor depression. She was operated on, but the resection was partial as the post operative tumor height was $12 \mathrm{~mm}$. Immunohistochemical study pleaded for pure somatotroph adenoma. Then after, she was treated by somatostatin analogues with a good result as only a $6 \mathrm{~mm}$ tumor located in the infundibular area, near the chiasm, persisted. The diagnosis of ectopic pituitary adenoma was made in retrospect.

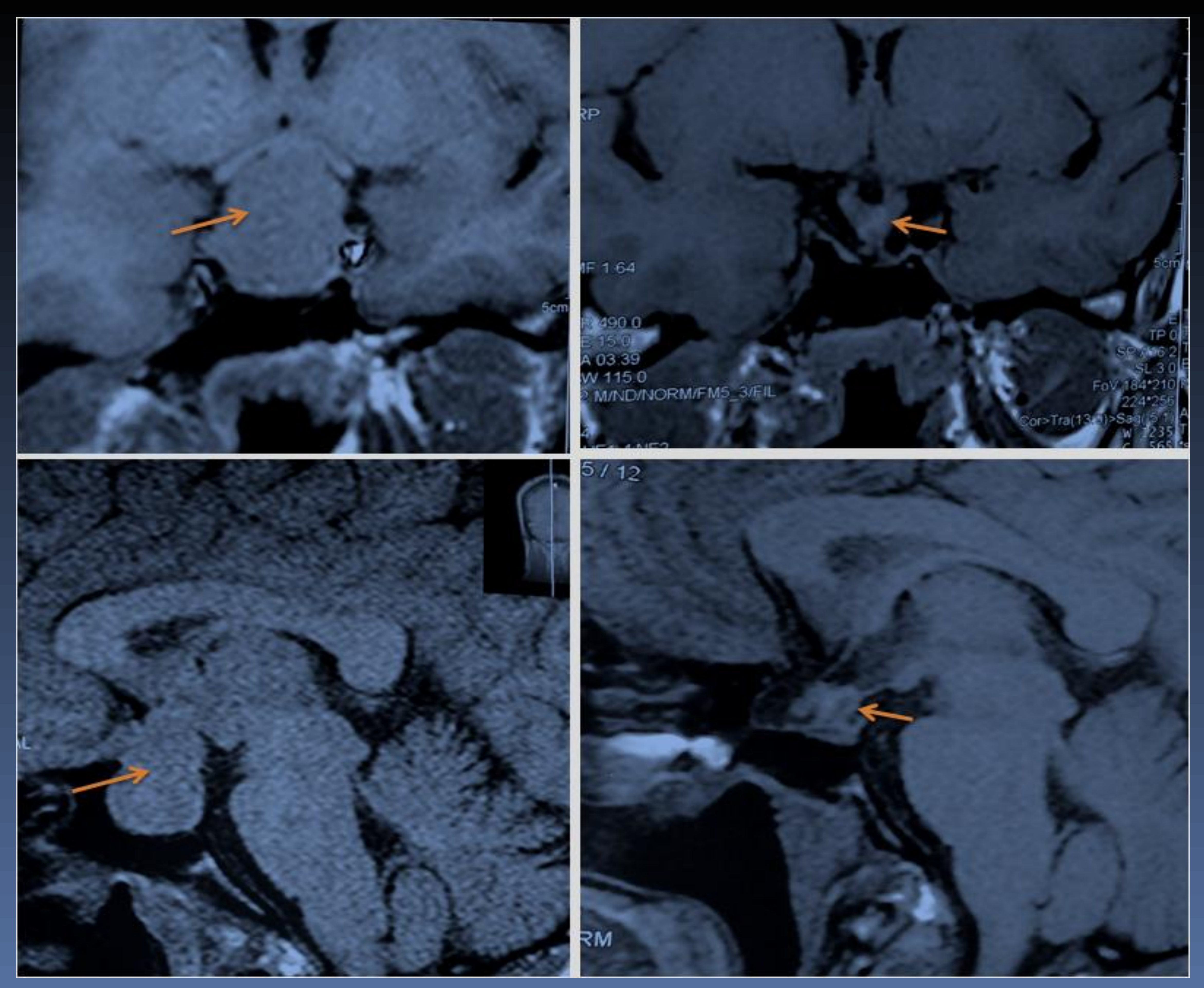

\section{Conclusion:}

The two somatotroph adenomas are considered as ectopic: One was in the sphenoid sinus and/or in the clivus, and the other one was in the infundibular area. The last one was diagnosed retrospectively after tumor shrinkage under somatostatin analogues. 